\title{
Sistema y Vida: El legado filosófico de Fichte
}

\section{Günter Zöller}

Traductor. Emiliano Acosta y Héctor Arrese Igor

\section{OpenEdition}

\section{Journals}

Edición electrónica

URL: http://journals.openedition.org/ref/669

DOI: 10.4000/ref.669

ISSN: 2258-014X

Editor

EuroPhilosophie Editions

Referencia electrónica

Günter Zöller, «Sistema y Vida: El legado filosófico de Fichte », Revista de Estud(i)os sobre Fichte [En línea], 12 | 2016, Publicado el 01 diciembre 2016, consultado el 10 diciembre 2020. URL : http:// journals.openedition.org/ref/669 ; DOI : https://doi.org/10.4000/ref.669

Este documento fue generado automáticamente el 10 diciembre 2020.

(c) EuroPhilosophie 


\title{
Sistema y Vida: El legado filosófico de Fichte
}

\author{
Günter Zöller \\ Tradución : Emiliano Acosta y Héctor Arrese Igor
}

$»[. .$.$] sólo son las leyes. «1$ Esta conferencia considera el propósito de Fichte de una "filosofía aplicada" que refleje en su entramado intrínseco el pensamiento filosófico (especulación) y la realidad externa a la filosofía (vida) -la cual también es previa y posterior a la filosofía. El foco está puesto en las "conferencias sobre diversos contenidos" del último año de vida de Fichte, anunciadas como tales y que constituyen aquel texto titulado como Doctrina del Estado. Publicado póstumamente este texto integra tanto el último estrato de la exposición de la doctrina de la ciencia como la fundamentación filosófica de la historia, el derecho, la religión y la política. La unión de sistema y vida mencionada en el título de esta conferencia se demuestra en relación a Fichte y en particular a sus últimas obras, tal como está desarrollada ejemplarmente en la Doctrina del Estado, en cuanto que implicación recíproca de una filosofía estructurada vitalmente y una vida determinada filosóficamente. Esta conferencia retrata la filosofía eminentemente práctica de Fichte ${ }^{3}$ en cuatro secciones: acerca de la relación entre el sistema y la crítica, entre el sistema y la auto-crítica, entre el sistema y la vida y, por último, entre la filosofía pura y la aplicada. En el centro del interés está siempre la validación vital del conocimiento en el último Fichte, lo cual debe ser visto como su legado filosófico. ${ }^{4}$

\section{Sistema y crítica}

La distinción entre crítica y sistema es de origen kantiano, su redefinición en cuanto oposición es una maniobra postkantiana. En la introducción a la Crítica de la razón pura, con motivo de la exposición de la "(...) idea de una ciencia particular, bajo el nombre de una crítica de la razón pura" ${ }^{5}$, Kant había diferenciado la fundamentación completa de la filosofía trascendental -en la forma de una crítica de la razón meramente teórica (especulativa) del "sistema"- de la filosofía trascendental misma que debía ser construida sobre ella. Él presentó allí la fundamentación por medio de la Crítica de la 
razón pura como algo completo en sí mismo, mientras que la construcción sistemática eventual era más bien un proyecto editorial que debía llevarse a cabo según el modo de los libros de enseñanza filosófica escolar. ${ }^{6}$

Es sabido que Kant mismo nunca se propuso completar la primera Crítica llevándola a un sistema de la filosofía trascendental. Es cierto que él puso en juego después una distinción entre crítica y sistema, justo al comienzo de la segunda edición de la Crítica de la razón pura (1787), cuya realización al menos parcial él mismo llevó a cabo. Frente a esta segunda distinción pertinente se ubica la Crítica -más precisamente: la Crítica de la razón pura- sobre cuyos fundamentos se erigen la "Metafísica tanto de la naturaleza como de las costumbres". ${ }^{7}$ A decir verdad Kant nunca llegó a publicar un "sistema de la naturaleza" ${ }^{8}$, salvo los Principios metafísicos de la ciencia natural (1785) y los intentos desesperados en este sentido en la Obra póstuma. Sin embargo, una obra de los últimos años de Kant como la Metafísica de las costumbres (1797) suministra el cumplimiento del segundo de ambos proyectos parciales de un sistema filosófico fundamentado críticamente ("sistema de la libertad"). ${ }^{9}$

En suma, la relación entre la crítica y el sistema en Kant no está restringida a la secuencia objetiva en el marco de una arquitectónica filosófica. Con la palabra 'sistema' Kant caracteriza no sólo una construcción mental filosófica en vista de su fundamentación fiable y su realización completa, sino también -incorporando un uso de la palabra y del concepto propio de una escuela filosófica- una concepción filosófica fundante (Lehbegriff), cuyo supuesto problemático o asertorio permite solucionar en principio problemas filosóficos más amplios. ${ }^{10} \mathrm{En}$ este sentido doctrinal en lugar de arquitectónico, el sistema de Kant es el del idealismo trascendental, que él también denomina como "idealismo formal" o "crítico" -en reacción a malentendidos anteriores. ${ }^{11}$

Mientras el concepto arquitectónico del sistema en Kant implica también la diferencia entre la crítica como propedéutica y preparación y el sistema como ejecución y elevación, en su concepto doctrinal del sistema, sin embargo, coinciden la crítica como criticismo y el sistema como filosofía crítica. La filosofía trascendental es para Kant filosofía crítica, tanto de acuerdo con su fundamentación (crítica) como según su realización (sistema). Se trata de una filosofía a partir del concepto filosófico fundante de la teoría del idealismo trascendental.

Los sucesores de Kant -los representantes del idealismo alemán- adoptan la diferencia arquitectónica kantiana entre la crítica propedéutica y el sistema enciclopédico. Sin embargo, lo convierten al mismo tiempo en lo opuesto. En esto vuelven contra Kant la interpretación que él mismo dio de su Crítica de la razón pura como una "mera" propedéutica para un sistema que aún debía ser elaborado, para así, primero, poder atribuirle a Kant el haber restringido su proyecto, si bien no a partir de un principio, al menos de acuerdo con los hechos, al trabajo de la crítica y no ya al sistema y, luego, poder, de este modo, poner en cuestión esta auto-restricción. El Kant reducido de esta manera a la crítica propedéutica se deja utilizar de modo excelente para el propio proyecto neokantiano de producir el sistema filosófico pendiente -sea éste como doctrina de la ciencia (Fichte), como filosofía de lo absoluto (Schelling) o como filosofía del espíritu (Hegel). ${ }^{12}$

En todos sus gestos y pretensiones de sobrepasar de modo propio y original a la obra crítica de Kant, los representantes postkantianos de la filosofía clásica alemana están sin embargo siempre dispuestos a confesar y reconocer su compromiso, por no decir su deuda para con la tarea previa de Kant. Este es el caso particular de Fichte, quien ya 
tempranamente y sin excepción hasta sus últimos días denomina a Kant no sólo como el motivador decisivo para la propia obra filosófica, sino también confirma la identidad esencial entre la vinculación kantiana de idealismo y criticismo y la propia teoría de la preponderancia del conocimiento frente a la cosa, del conocimiento y el deber frente al ser. ${ }^{13}$ Aquí es Fichte en especial quien comparte la disociación de Kant entre el criticismo estructurado de modo idealista -o el idealismo realizado críticamente- de un realismo (trascendental) desenmascarado y denigrado como dogmatismo. La equiparación acoplada que hace Fichte entre el criticismo y el idealismo, así como entre el dogmatismo y el realismo, lo lleva de comienzo a fin a considerar como una filosofía falsa o una no-filosofía a todas aquellas que no son exclusivamente idealistas. Entre ellas, sobre todo la filosofía natural de Schelling, pero también el realismo lógico de Bardili o el populismo de Fr. Nicolai. ${ }^{14}$

Fichte comparte también con Kant, desde sus comienzos en Zúrich y Jena, el zeugma estratégico de la filosofía trascendental y la filosofía moral críticas. Si bien el sistema completo "de la libertad" -una fórmula programática que se encuentra tanto en Kant como en Fichte- ${ }^{15}$ se suspende en ambos filósofos por diferentes motivos, Kant y Fichte están de acuerdo en la orientación última de la filosofía teórica hacia la filosofía práctica, del conocimiento al querer, del pensamiento al hacer, del concepto del objeto al de fin y del mundo sensible al mundo moral. ${ }^{16}$ Tanto en Kant como en Fichte el primado de la razón práctica que ellos exigen, conciben y amplían de modo diferente, no se da de manera reductiva ni monopólica, sino que es la expresión de un orden normativo y una jerarquía de intereses que coloca al pensamiento al servicio del actuar, a la determinación del objeto al servicio de la determinación de la voluntad y al conocimiento del objeto al servicio de la realización de la libertad.

Más allá del consenso doctrinal entre Kant y Fichte sobre la reconciliación del criticismo con el idealismo, Fichte sigue también la praxis de Kant, para establecer expresamente su pensamiento propio original por medio de una reflexión preliminar de tipo metódico y metodológico ("crítica"). Tanto en el primer Fichte (1793-1799) como en el último (1809-1814), se encuentra, sumado a su propósito central de una filosofía trascendental completada de modo actualizado ("doctrina de la ciencia in specie" ${ }^{17}$ ), todo un corpus de obras destinadas a servir de introducción a la filosofía primera. La proto-filosofía crítica abarca en Fichte diferentes lugares textuales: introducciones a la doctrina de la ciencia en sentido estricto y propio, tratamiento de los hechos psicológicos relevantes para la doctrina de la ciencia ("hechos de la conciencia"), tratamiento diferencial del pensamiento trascendental puro lógico y específicamente trascendental ("lógica trascendental").

Fichte actúa en conformidad con Kant al sujetar el criticismo de la filosofía trascendental, continuada como teoría de la ciencia, a un comportamiento espiritual y a una actitud intelectual (Denkart) generales, ${ }^{18}$ exigidas y promovidas por el pensamiento autónomo a partir de la destitución de la tradición, la convención y el prejuicio. El imperativo ilustrado del pensamiento crítico vale aquí no sólo para la forma de la praxis filosófica, que debe consistir en el pensamiento propio, sino que abarca también los contenidos del filosofar independiente. Es la continuación de la máxima de investigación conocida como el Principio de Vico, que declara como convertibles a lo conocido correctamente (verum) y aquello que se ha hecho por sí mismo (factum). Kant y Fichte unen el conocer y el saber al hacer-por-uno-mismo y al actuar-por-uno-mismo. Para Fichte, que en esto sigue a Kant, el idealismo crítico es 
performativo y está asentado sobre la actividad, que además debe ser una actividad propia, y se orienta teóricamente a la espontaneidad y prácticamente a la libertad.

\section{Sistema y autocrítica}

La relación íntima y la identidad de contenido entre la crítica y el sistema en Fichte afecta no sólo a la estructura interna del sistema filosófico fundamentado críticamente. También es crítica en Fichte la relación de la filosofía consigo misma. En cuanto filosofía crítica, la teoría de la ciencia es, por ponerla en una palabra, autocrítica: está relacionada de modo reflexivo y productivo con las posibilidades y límites de su capacidad conceptual. También desde esta perspectiva Kant cumple el rol, para Fichte, de ser caso precedente y modelo. La filosofía crítica es para Kant esencialmente la autocrítica de la razón. Desde la filosofía trascendental en sentido estricto (Crítica de la razón pura), pasando por la filosofía moral crítica (Crítica de la razón práctica), hasta la filosofía crítica de la naturaleza y del arte (Crítica de la capacidad de juzgar), siempre se trata en Kant del origen, las posibilidades y los límites del uso de la razón en general y del uso "puro", libre de la experiencia, de la razón en particular.

En Fichte la autocrítica filosófica se convierte en un programa y un método. La doctrina de la ciencia debe proporcionar los primeros principios de todo conocimiento y al mismo tiempo allí debe participar en la fundamentación de la forma propia de conocimiento. Conceptos artificiales como "poner", "acción-hecho" (Tathandlung) e "intuición intelectual" y formaciones conceptuales tales como "ver espiritual" y "ojo interior", sirven a la auto-justificación estratégica de la doctrina de la ciencia, en términos de un meta-conocimiento evidente de los últimos fundamentos de todo conocimiento junto con los objetos allí involucrados. ${ }^{19}$

También la diferenciación entre, por un lado, el sujeto genérico articulado artificialmente del pensar y del actuar (Yo), y, por otro, su instanciación individual y concreta por medio de cada sí-mismo particular, pertenece a la situación autocrítica de la doctrina de la ciencia que se halla más allá -o más bien más acá- de la psicología y la antropología. Del mismo modo que el Yo de la doctrina de la ciencia no debe ser confundido con el yo de su autor, en la doctrina de la ciencia no se trata de otro yo individual, sino que se dirige a un portador idéntico-invariante del conocimiento y del querer basado en el conocimiento, a cuyo conocimiento y reconocimiento la doctrina de la ciencia quiere guiarnos.

La dimensión autocrítica de la doctrina de la ciencia se demuestra ante todo en su permanente transformación por medio de su autor, quien expone la teoría trascendental del conocimiento durante dos décadas una y otra vez de un modo diferente. El motivo externo para la exposición modificada está dado más que nada por los malentendidos y opiniones erróneas, que le tocaron en suerte a la doctrina de la ciencia en su primera forma publicada: el Fundamento de toda la teoría de la ciencia de 1794/95. La Nueva exposición de la doctrina de la ciencia o Wissenschaftslehre nova methodo, expuesta posteriormente entre 1796 y 1799, se enfrenta a la comprensión errónea del Yo trascendental, de tipo individual-psicológica, por medio de la reducción de la Yoidad de principio a una auto-relación pura práctica ("querer puro") y la reducción de la individualidad a la sociabilidad ("mundo espiritual").

En las obras posteriores de Fichte influye de modo aún más dramático y directamente traumático la interpretación errónea de su concepto moral de Dios como ateísmo (Disputa del ateísmo, 1798-1799). Esta interpretación lo pone indirectamente y de modo 
mediato sobre la picota y da lugar a su escepticismo frente a la mediación escrita de su propia filosofía trascendental avanzada (doctrina de la ciencia). Luego de 1799 Fichte prácticamente renuncia a publicar en forma de libro la continuación de su trabajo sobre la doctrina de la ciencia y limita la comunicación de la misma a numerosas y extensas series de conferencias, dictadas frente a un público privado, con excepción de 1805, siendo profesor en Erlangen, así como una vez en 1807 en la Universidad de Königsberg y a partir de 1810 como profesor de la recién fundada Universidad de Berlín.

En los años que van desde 1800 hasta 1814 Fichte expone su doctrina de la ciencia no menos de doce veces -y siempre de modo distinto, con una terminología y conceptualidad cambiantes, con una construcción diferente, con diversas referencias históricas y sistemáticas. La exposición de la doctrina de la ciencia, tanto serial como variada, no sólo da cuenta de la situación del discurso filosófico del siglo XIX, que se modifica a sí mismo. Fichte recurre deliberadamente a expresiones y conceptos que se originan en el arsenal de sus competidores y oponentes -desde el concepto de la vida en Jacobi hasta el de lo absoluto en Schelling. ${ }^{20}$ Sin que Fichte entonces concuerde con estos autores asimila el propio discurso a la situación lingüística e intelectual de su tiempo con la intención de permanecer en diálogo filosófico y de ejercer una influencia en adelante, además de cumplir con su rol de motivador del idealismo postkantiano. Sin embargo, la estrategia de Fichte de presentar siempre de modo diferente la doctrina de la ciencia, además del empréstito ocasional y oportunista de teoremas extraños, tiene también fundamentos metodológicos profundos y consecuencias sistemáticas trascendentes. Como consecuencia de su carácter eminentemente crítico y en especial autocrítico, la doctrina de la ciencia de Fichte no constituye una doctrina completa, que podría ser expuesta y divulgada. El elemento particular de la doctrina de la ciencia no es para Fichte la letra rígida y fija, sino el espíritu movible, flexible. Por lo tanto la exposición de la doctrina de la ciencia no está al servicio de la instrucción y el adoctrinamiento, sino de la iniciación e inspiración. La doctrina de la ciencia no se dirige a recipientes pasivos, sino a co-ejecutores y co-realizadores espontáneos de un pensamiento filosófico que consiste esencialmente en la realización de sí mismo y en cada adquisición individual y totalmente propia de conocimiento.

Con su forma de exposición siempre diferente, Fichte da cuenta de su conocimiento central: que el saber no consiste en el reflejo de datos previamente dados, sino en la producción de estructuras normativas, es decir, objetos debidos, que se pueden conocer y reconocer como objetos o cosas desde el punto de vista teórico o como fines y metas desde una disposición práctica. Pero esto vale, más allá del tabú de repetición dominante, no sólo en relación a su público, que en primer lugar debe oír y escuchar y recién secundariamente leer y releer -posteriormente o a modo de sustituto. También para el mismo Fichte la repetición y la reglamentación del pensamiento movidomoviente representa un peligro cognitivo, que amenaza con convertirse en un pensamiento detenido. Para poder evitar la objetivación siempre al acecho y la osificación del propio pensamiento autónomo y hacer justicia a la genuina agilidad del pensamiento, se necesita del cambio ininterrumpido en la comunicación de la doctrina de la ciencia -ningún concepto debe solidificarse, ninguna comprensión debe fijarse, ningún proceso de pensamiento debe gelificarse.

La exigencia de modificación desde el punto de vista del productor así como del receptor da a la exposición de la doctrina de la ciencia un dinamismo intrínseco: nada debe ser simplemente repetido; la forma de exposición debe ser modificada sin 
interrupciones, de modo tal de que su contenido -el contenido espiritual de la doctrina de la ciencia- permanezca conservado como tal. Pero la alteración y la variación no son ya también progresión y perfeccionamiento. A fin de que el cambio se convierta en progreso y la modificación en desarrollo, es menester un movimiento deliberado y un criterio para el movimiento orientado hacia el fin. El estado final que se busca de la doctrina de la ciencia no debe ser de nuevo un producto final. No puede haber una exposición definitiva, sino antes bien el esfuerzo continuo y deliberado para lograr la comunicación efectiva del concepto central de la doctrina de la ciencia, que consiste en el carácter crítico-idealista del conocimiento en cuanto tal.

Si por tanto la doctrina de la ciencia no es, según su esencia, ergon sino energeia, no es opus sino operari, no obra (Werk) sino producir o efectuar (Wirken), entonces está prohibida la adopción de un proceso de desarrollo de la sucesión cronológicamente manifiesta de sus diferentes exposiciones. Puede ocurrir que a la base de las exposiciones de los últimos años haya ciertas comprensiones y experiencias que son desconocidas para las primeras versiones. Sin embargo ellas serían antes bien comprensiones y experiencias respecto de las posibilidades y límites de la exposición de la doctrina de la ciencia y no tanto de la doctrina de la ciencia misma -de su núcleo esencial, idéntico, metódico-doctrinal y sistemático en cuanto que teoría de los principios de todo el conocimiento y de todo lo conocido.

La impresión contraria de un desarrollo dramático de la doctrina de la ciencia misma y en cuanto tal -en especial su desarrollo posterior desde la filosofía trascendental crítica hasta una metafísica post-crítica o incluso una mística anti-crítica-, que puede deducirse del trabajo de los primeros intérpretes y exégetas, más bien se retrotrae a una lectura selectiva de textos y fragmentos, gracias a la cual los procesos de pensamiento continuos y comprehensivos se deforman en expresiones doctrinales de tipo dogmático. Del mismo modo que el work-in-progress de la doctrina de la ciencia no conoce ningún estado final fáctico, esto prohíbe también la fijación a una única exposición, no importa cuánto se destaque por la originalidad y calidad. Lo que precisamente contradice el espíritu de la doctrina de la ciencia es aislar artificialmente y preparar con gran calidad técnica siguiendo criterios de la doxografía partes de un texto de Fichte que es más abarcador que los pasajes en cuestión y que se halla en un proceso continuo de pensamiento.

En orden a la exculpación de los primeros intentos de interpretación del último Fichte, debe decirse que hasta hace poco -esto es, hasta el cierre de la J. G. Fichte-Gesamtausgabe de la Academia Bávara de las Ciencias (2012)- todo el volumen y la magnitud del trabajo realizado por Fichte durante dos décadas en su exposición de la doctrina de la ciencia no se tenía en cuenta ni se conocía. De este modo podía parecer que algunas exposiciones posteriores, en particular la monumental segunda conferencia de la doctrina de la ciencia del año 1804, habían producido aportes filosóficos singulares y definitivos no superados fácticamente. Pero en el contexto completo de las exposiciones últimas así como en las muchas versiones previas, cada exposición individual de la doctrina de la ciencia deviene una estación entre muchas otras de un recorrido que seguramente no está caracterizado por el escalamiento y el remiendo y seguro que tampoco por la conversión y la retractación, sino más bien por la alteración y la variación. 


\section{Sistema y vida}

Aun cuando la forma de exposición serial y en clave de variaciones de la doctrina de la ciencia no conoce ninguna versión definitiva ni movimiento progresivo ascendente alguno, en esta sucesión de unas dieciséis versiones pueden distinguirse distintas fases. La división en dos fases, que era usual en el pasado, es decir entre el Fichte de Jena y el último Fichte de Berlín, debe no obstante ser revisada a la luz de la obra completa editada críticamente. Puede añadirse otra fase para el período que Fichte pasa en Berlín con pocas excepciones (Erlangen en 1805, Königsberg en 1807), luego de su salida forzosa de Jena. Esta fase establece una diferencia dentro de la secuencia de conferencias sobre la teoría de la ciencia, entre los años intermedios (1800-1805: siete conferencias) y los últimos años de Berlín (1810-1814: cinco conferencias), a los que conecta la conferencia de Königsberg sobre la doctrina de la ciencia (1807). La sucesión histórica que de allí resulta, a saber: fase primera, media y última ${ }^{21}$, se presenta también sistemáticamente en tres partes a partir del concepto que en cada fase sirve como concepto conductor para las exposiciones en particular: desde el Yo (absoluto) en el primer Fichte a través del ser (absoluto) en el medio hasta la vida (absoluta) en el último Fichte. En todas estos tres casos y fases, el concepto conductor correspondiente sirve a la articulación conceptual de la instancia de fundamentación última del conocimiento en vista de su validez, independientemente de sus circunstancias contingentes y de las condiciones casuales desde el punto de vista de los sujetos y objetos involucrados fácticamente en el conocimiento.

La división triádica en fases de las dieciséis exposiciones de la teoría de la ciencia tiene una estructura que se repite y que sigue el esquema ABA -o más bien ABA'-. Luego del foco de la exposición de la doctrina de la ciencia durante los primeros años sobre la teoría del Yo trascendental, con su doble tema del pensar y el querer o del conocer y el actuar, el centro de gravedad cambia en el Fichte medio hacia la concepción lógicotrascendental del conocimiento en su cualidad "absoluta", válida a nivel teórico, para incluir de nuevo en las últimas exposiciones de la doctrina de la ciencia la impronta práctica de la estructura del querer en la fundamentación principal del saber. Las fases primera y tercera en el proceso de exposición de la doctrina de la ciencia concuerdan entre sí en que en ellas la exposición de la doctrina de la ciencia está vinculada con obras de cuño sistemático que preceden y siguen a la doctrina de la ciencia en sentido propio y estricto tanto en cuanto propedéutica como en cuanto aplicación. Esto vale en particular para las exposiciones de las fases primera y última, las cuales son completadas en cada caso por una doctrina del derecho y de la moral (Fundamento del Derecho Natural de 1796/1797; Sistema de la Doctrina de las Costumbres de 1798; Doctrina del Derecho de 1812; Doctrina de las costumbres de 1812). Frente a esto las exposiciones de la doctrina de la ciencia del periodo intermedio se hallan sistemáticamente aisladas: una circunstancia que se retrotrae a la falta de integración de las primeras conferencias de Berlín en un programa de enseñanza universitario, que Fichte, previamente en Jena y más tarde en Berlín, fijó en el marco de una exposición completa curricular del sistema de la filosofía.

En la división triádica grosso modo de la historia de la exposición de la doctrina de la ciencia se manifiesta así una curva de desarrollo que otorga a la doctrina de la ciencia expuesta una estructura global cíclica. Con la conexión entre vida, conocer y querer el Fichte último regresa, apoyado en el fundamento de su fase media que incluye la reconciliación entre el conocer y el absoluto, a los temas y perspectivas centrales de su 
fase primera. La relación fundante y repetitiva entre las exposiciones primera y última de la doctrina de la ciencia vuelve a expresarse en el hecho de que el último Fichte remite, si bien de modo sumario y breve, a las doctrinas y detalles de sus versiones primeras, en especial a la única versión publicada de 1794/1795, pero sin retomar su agudeza y complejidad constructiva. Tanto en el Fichte último como en el Fichte medio aparece en lugar de la preferencia por la deducción, la derivación y la demostración, una inclinación hacia la monotonía y lo monotemático, lo cual serviría para la exposición insistente de nociones y posiciones centrales.

El caso extremo de la abreviatura y la condensación en el Fichte último es la reducción radical de todas los elementos teóricos de la doctrina de la ciencia a "un pensamiento" ${ }^{22}$, el pensamiento de que el conocimiento y sólo el conocimiento es la manifestación de lo absoluto. La reducción formal del trabajo de toda la vida de Fichte no sirve en realidad a la introducción argumentativa a la teoría fundamental de la doctrina de la ciencia (última), la cual tampoco, para decirlo de algún modo, la debe reemplazar. Más bien sirve al giro perfecto para que sea eficiente la memorización, sobre cuyo fundamento entonces el sistema crítico de la doctrina de la ciencia debe ser reconstruido.

Considerando el tema a partir del doble trasfondo de las exposiciones primera y media de la doctrina de la ciencia, el aporte original de las exposiciones del período último de la doctrina de la ciencia no reside en los detalles doctrinales y los complementos específicos, sino en la auto-interpretación crítica de la doctrina de la ciencia en general y en particular de su localización en relación con la realidad previa, externa y posterior a la filosofía (vida). En las conferencias del período último sobre la doctrina de la ciencia Fichte reflexiona con más fuerza que en las exposiciones anteriores sobre la forma y el modo, pero también sobre el sentido y el fin del filosofar, el cual se aparta claramente de la realidad vital del mismo modo que está relacionado intrínsecamente con ella.

La perspectiva pre-filosófica del Fichte último puede ser en especial captada en el texto de una conferencia del año 1813, la cual conecta la representación sumaria de la doctrina de la ciencia en su estado de exposición cronológicamente y de facto último con la aplicación explícita de la filosofía a la vida, de la doctrina de la ciencia a la realidad efectiva en los ámbitos de la historia, el derecho, la política y la religión. Respecto de esta fusión de la doctrina de la ciencia pura y aplicada, fundamentada así como realizada en aquellos ámbitos mencionados previamente, en las "Conferencias de diverso contenido", ${ }^{23}$ editadas recién luego de la muerte de Fichte bajo el título inauténtico de Doctrina del Estado (1820), se trata del legado filosófico de Fichte, su Opus Postumum, que no sólo expresa como en un espejo cóncavo la disposición sistemática de Fichte en la doctrina de la ciencia, sino que también conduce a su realización. ${ }^{24}$

\section{La filosofía pura y aplicada}

La exposición sumaria de la doctrina de la ciencia en la parte de la apertura de la Doctrina del Estado retoma absolutamente la concepción del conocimiento como la "esencia de la imagen", ${ }^{25}$ que ya se encuentra la fase media de la exposición de la doctrina de la ciencia. ${ }^{26}$ Con la identificación entre conocimiento e imagen el Fichte medio y el último articulan, por un lado, el carácter del conocimiento producido de modo explícito y fabricado libremente, que no refleja lo que ya está dado mecánica y automáticamente, sino que ante todo pone o bien "forma" el ser objetivo -y por ello 
independiente. Por otro lado, la equiparación entre conocer y formar indica el carácter de deducido (en vez de originario) de los objetos de conocimiento, que surgen sólo en y a través de la tarea formadora del conocimiento. En la medida en que el Fichte medio y el último formulan el idealismo crítico de la doctrina de la ciencia, validado desde el comienzo, como idolatría [Idolismus] e imaginismo [Imagismus], Fichte puede al mismo tiempo desenmascarar el realismo alternativo y el dogmatismo que se opone a la doctrina de la ciencia como una confusión entre imagen y cosa.

Pero, para el concepto de imagen propio del último Fichte, la confusión entre la imagen y la cosa por medio de la consciencia pre-filosófica y su "visión natural del mundo" ${ }^{27}$ es más importante que la discusión intra-filosófica sobre la estructura fundante de la filosofía -en torno al idealismo o el realismo, el criticismo o el dogmatismo. Lo que se le aparece a la consciencia natural como un mundo de objetos existentes con independencia de la consciencia que tengamos de ellos ("sistema de cosas" ${ }^{28}$ ), se demuestra en la reflexión filosófica crítica como un orden de apariencias puestas en el conocer, por medio del conocer y para el conocer ("sistema de imágenes" ${ }^{29}$ ).

Sin embargo el último Fichte no se contenta con la reducción crítica de los objetos a las apariencias y de las cosas a imágenes. A la reducción crítico-idealista del sistema de las cosas al sistema de las imágenes, se le agrega en la exposición última de la doctrina de la ciencia (tal como se da en la Doctrina del Estado) la reducción adicional de las imágenes-cosas a las leyes de su generación. La ley genérica de la formación de la imagen o de la generación del objeto es concebida por Fichte como ella misma constituida gráficamente -como "imagen ante todo" o "imagen originaria" 30 para la formación de imágenes. La comprensión critico-idealista sobre el status derivativo de cosas presuntamente independientes en tanto que imágenes generadas meramente por medio de leyes complementa y rectifica el conocimiento fáctico de la visión natural del mundo por medio del "conocimiento genético" ${ }^{11}$ de la cosmovisión filosófica. En sentido estricto ni el "sistema de las cosas" ni el "sistema de las imágenes" tienen existencia para Fichte. ${ }^{32}$ En realidad sólo hay leyes. Las imágenes-cosas o las cosas-imágenes deben ser consideradas como la manifestación ("Ersichtlichkeit")

El regreso gradual desde las cosas a las imágenes y desde las imágenes a las leyes termina en el último Fichte-y de modo ejemplar en la Doctrina del Estado última- en un concepto de ley, por su parte, estructurado doblemente. En relación a las leyes, por medio de las cuales las imágenes-cosas surgen en primer lugar, se trata de leyes del ordenamiento natural y de sus objetos ("leyes naturales" ${ }^{34}$ ). El pensar sobre las cosas, localizable en este estadio, vale para Fichte como deficitario. El recurso a legalidades naturales repite para Fichte, con vistas a las leyes operativas, la fijeza del pensamiento dogmático de la supuesta facticidad de las cosas, criticada en el pasado. La sublimación deficitario-dogmática de las leyes naturales en leyes sin más -en realidad una "nofilosofía" ${ }^{35}$ es caracterizada por el último Fichte con la fórmula programática tomada del primer Schelling: "filosofía natural" ${ }^{36}$, que aquí representa en general el pensamiento erróneo y cosificado y en particular la cosificación de la naturaleza en la instancia innegable de la donación de la ley y de la imagen.

Por el contrario, lo que caracteriza el principio crítico-idealista de la doctrina de la ciencia es el hecho de superar la legalidad de la naturaleza hacia otro tipo de ley, la cual no sólo actúa de modo ciego, sino que entra en acción por medio de la razón y la reflexión como ley práctica ("ley moral" ${ }^{37}$ ), que rige el actuar y además, por medio de la acción de mediación de la voluntad, también causa la acción. En relación con la legalidad del querer y el actuar, para el Fichte de la Doctrina del Estado la legalidad de la 
naturaleza y sus objetos es sólo el fundamento ("materia", "esfera" ${ }^{38}$ ) de la actividad extra- y sobrenatural, dimensionada moralmente. De acuerdo con la concepción antidualista de Fichte lo material es para lo espiritual solamente el funcional estar-frente [das funktionale Gegenüber], que se opone a lo espiritual del mismo modo que puede y debe salirle al encuentro.

Con el ascenso desde la legalidad natural a la legalidad moral la Doctrina del Estado acompaña en Fichte el pasaje desde lo teórico a lo práctico, del conocimiento de objetos y la determinación de los objetos a poner fines y determinar la voluntad. En cuanto conocimiento práctico, el conocimiento empuja hacia el querer y el actuar conforme a normas específicas del querer y el actuar ("ley moral"39). La función causal de la libertad, como la iniciadora incondicionada del actuar práctico y de la producción a él asociada de la realidad objetiva ("comienzo absoluto del ser" ${ }^{40}$ ), es determinante para la legalidad del querer y del actuar, a diferencia de la legalidad de la naturaleza. Para el último Fichte la libertad es un principio cosmológico, como lo había sido anteriormente para Kant ("fundamento independiente de [...] determinaciones del ser" ${ }^{41}$ ). La voluntad considerada como radicalmente libre y absolutamente espontánea está por sobre toda determinación natural ("ninguna naturaleza sobre la voluntad"42) y sobre todo principio de toda naturaleza y todo ser ("ninguna naturaleza y ningún ser salvo por medio de la voluntad [...]"43). La naturaleza no es, en la perspectiva práctico-idealista de Fichte, un origen y un fundamento, sino un resultado y una consecuencia (ninguna [naturaleza] entonces como principado [Principiat]" $\left.{ }^{44}\right) .45$

La perspectiva primariamente práctica de la doctrina de la ciencia dada en general en el último Fichte y, en particular, en la Doctrina del Estado, retoma la focalización primera de los años de Jena, puesta en el primado de lo práctico y la función de principio que tiene la voluntad. También la relegación de la naturaleza a, por un lado, proveedora del material de la acción libre y, por otro, arena para la comprobación moral del sí-mismo tiene su impronta previa en el Fichte de Jena. Lo que es nuevo en el último Fichte frente a la versión primera de la doctrina de la ciencia como idealismo práctico es la fundamentación última de la legislación moral en una instancia de fundamento último llamada a evitar el recurso a clases cada vez más altas de leyes. Con esto el último Fichte se enlaza con las explicaciones orientadas a lo absoluto, al ser y al Dios de la etapa media de Fichte.

El recurso a un absoluto en el último Fichte está también fundamentado de modo funcional, como el intento filosófico de reivindicar el carácter absoluto de las leyes de la libertad, a fin de proteger su validez del escepticismo epistémico, el relativismo ético y el nihilismo moral. Tanto en la Doctrina del Estado como en las exposiciones separadas de la doctrina de la ciencia Fichte llega incluso tan lejos como para introducir un ser absoluto ("Dios") a fin de vincularlo con las leyes del pensamiento del entendimiento ("Dios mismo existe en el conocimiento"46), a fin de recuperar de modo idealista la realidad aparentemente absoluta de un ser detrás del deber. "Dios", "lo absoluto" o "el Ser" se confirman de este modo en cuanto que indicadores y modos de expresión de la validez incondicionada de la ley (moral). ${ }^{47}$ También aquí se confirma la identidad esencial y la concordancia substancial entre el último y el primer Fichte. Ya en la exposición de Jena de la doctrina de la ciencia Fichte había descrito el momento de la incondicionalidad en la actividad del Yo ("poner") por medio del título "absoluto" ("el Yo absoluto"48), sin con ello afirmar una entidad propia separada de la acción trascendental del Yo. 
El último Fichte vincula la impronta práctica de la doctrina de la ciencia, ya conocida desde su primera fase y ahora retomada, con su capacidad de producción práctica. La doctrina de la ciencia es por cierto también en cuanto teoría trascendental del querer y el actuar nada más que una teoría separada categorialmente del querer y el actuar. Pero para el último Fichte la doctrina de la ciencia se abalanza más allá de sí misma desde el saber sobre el querer hacia el querer mismo y en particular desde el saber sobre el querer moralmente cualificado hacia el querer moralmente cualificado al actuar conforme a él ("una vida moral" ${ }^{49}$ ). El último Fichte concibe el paso desde la teoría fundamentada filosóficamente a la praxis determinada posteriormente como el tránsito desde la ciencia a la sabiduría y ve en el hecho de que la doctrina de la ciencia se supera a sí misma volviéndose "doctrina de la sabiduría" ${ }^{50}$ la culminación de la filosofía en la vida. La filosofía acabada es para el Fichte de la Doctrina del Estado la "filosofía aplicada" 51

Hablando en sentido estricto, la aplicación de la filosofía yace pues fuera de la filosofía. En cuanto aplicada la filosofía ya no es más filosofía, sino vida -idealiter una vida determinada por la filosofía. De acuerdo con la concepción del último Fichte, quien en esto adhiere a sus propias ideas del primer periodo, la vida marcada por el saber filosófico y su sabiduría práctica es la vida modelada éticamente. De todos modos, la filosofía, aun cuando sea una doctrina de la ciencia devenida doctrina de la sabiduría, no puede simplemente prescribir su aplicación ética ni intervenir por decreto. Más bien la aplicación de la filosofía debe resultar en cada caso algo individual y surgido de la propia iniciativa. El modo de la instrucción filosófica en general y de la educación práctica en particular es para Fichte, desde sus comienzos en Jena, un llamado a la libertad y responsabilidad de cada uno ("exhortación"52).

Sin embargo, Fichte desarrolla en su Doctrina del Estado del periodo último otra concepción, que se añade a la anterior, de la filosofía práctica y aplicada, la cual reivindica un dominio de aplicación para la filosofía misma y en cuanto tal. La "filosofía aplicada" de la Doctrina del Estado del último periodo es una filosofía sobre la aplicación: una reflexión filosófica sobre las condiciones bajo las que puede lograrse - o ante todo es posible- la realización vital del saber práctico en la forma de la "vida moral". La tesis central del último Fichte en su Doctrina del Estado consiste en que la vida ética -eticidad vivida- necesita de un marco social, dentro del cual se puede vivir efectivamente de una manera ética, lo que en primer lugar significa que se puede actuar éticamente. La Doctrina del Estado, en cuanto "filosofía aplicada", no tiene que ver con los principios universalmente válidos y generales de la eticidad, que son el objeto de una ética construida explícitamente (doctrina de las costumbres). Más bien se trata en ella de las condiciones concretas, específicas, históricas, bajo las cuales puede llevarse a cabo fácticamente el actuar ético de acuerdo con el idealismo ético de Fichte (sistema de la doctrina de las costumbres). El marco general para la moralidad posible es para Fichte el dominio del derecho como un ordenamiento social impuesto políticamente, que posiciona a cada uno en relación con sus iguales de un modo tal que está garantizado el espacio para la libertad, para el querer y el actuar éticos libres para cada uno de los participantes. Desde el punto de vista de su realización la Doctrina del Estado de Fichte constituye entonces una filosofía política de la evolución histórica del derecho, en cuanto principio, y de los derechos como su configuración. El interés particular de Fichte reside allí en el avance teórico y la realización práctica de la igualdad en relación con el derecho y los derechos en el transcurso de la historia. Desde la perspectiva jurídica el curso de la historia lleva a una doble igualdad social: la igual participación de 
todos en la regulación legal de la vida social ("igualdad del derecho") y de la participación de todos en los mismos derechos ("igualdad [...] de los derechos" ${ }^{53}$ ). En la filosofía política de la historia de la Doctrina del Estado la reunión liberal [freiheitlich] de la legalidad y la igualdad no es un fin en sí mismo ni tampoco el fin último del desarrollo histórico. El dominio del derecho expandido racionalmente ("el imperio del derecho" ${ }^{54}$ ) coloca por su parte todo el fundamento social de la moralización masiva y la eticización [Ethisierung] extensiva de la existencia humana individual y trans-individual. La libertad general de la injusticia y el poder capacita y promueve, según Fichte, la posibilidad de una auto-compleción éticamente genuina del ser humano. El último Fichte localiza el punto preciso del tránsito desde la regulación legal a la disposición ética en el necrosarse finito del Estado en cuanto institución que ejerce la coacción legal exterior. La comprensión creciente de los ciudadanos formados políticamente y con convicciones cívicas acerca del sentido liberador y el fin del orden jurídico y político lleva, según Fichte, a la expansión de la acción voluntaria conforme al derecho a partir de la convicción cívica y con ello a la renuncia fáctica a los instrumentos de la coacción legal (poder sancionado, castigo).

De todos modos el último Fichte evita la confusión entre el derecho y la moral (ética) en la perspectiva del Estado que se aniquila a sí mismo - en esto sigue adhiriendo a su obra temprana de Jena. La convicción legal restante del Estado como institución coactiva afecta de aquí en adelante el actuar exteriormente conforme a derecho, excluyendo la motivación ética pura. Sólo sobre el fundamento del estado (estatal-)civil pacificado voluntaria y legalmente puede tener lugar aquella transformación adicional que deja surgir una comunidad ética más allá de la comunidad puramente legal. De modo similar, Kant ya había distinguido, en su escrito postrero sobre la religión, entre la sociedad estricta legal y civil ("Estado") y la comunidad ética civil ("iglesia") y allí había identificado a la república de la virtud como global y al Estado de derecho como territorial..$^{55}$

El Kant y el Fichte últimos comparten la división institucional y conforme a principios entre Estado y religión así como entre derecho y moral, deudora de la ilustración europea - aun cuando en ambos las esferas separadas de validez de lo jurídico y lo ético se integran en un desarrollo progresivo histórico-filosófico que debe conducir desde la exterioridad del derecho a la interioridad de la ética. En especial con respecto a Fichte se debe tener presente que el tratamiento sistemático de la aplicación de la filosofía a las esferas del derecho y la ética desemboca en una filosofía práctica que permanece comprometida con el pensamiento crítico. Precisamente así como la doctrina de la ciencia en sus últimas exposiciones no se transforma ni en metafísica ni en mística, así tampoco la teoría del derecho y de la moral del último Fichte degenera en un romanticismo político y un socialismo ético.

\section{NOTAS}

1. StL, GA II/16, 22 (Die Staatslehre, oder über das Verhältnis des Urstaates zum Vernunftreiche 1813).

2. StL, GA II $16,15$. 
3. Acerca del concepto de la filosofía práctica en Fichte, ver Zöller, G. \& von Manz, H. G. (eds.) Fichtes praktische Philosophie. Eine systematische Einführung. Hildesheim: Olms, 2006.

4. Los argumentos siguientes se basan en investigaciones llevadas a cabo a lo largo de muchos años y en publicaciones del autor, las que serán indicadas en el transcurso del texto.

5. KrV B 24.

6. KrV B 22s. Acerca del concepto de lo trascendental en Kant, ver Zöller, G., "Conditions of Objectivity. Kant«s Critical Conception of Transcendental Logic", en: Yearbook of German Idealism/ Jahrbuch des deutschen Idealismus (en prensa).

7. KrV B XLIII. Ver también KrV A XXI.

8. $\mathrm{KrV}$ A 690/B 718.

9. KrV A 815/B 843.

10. Al respecto ver Zöller, G. “»Die Seele des Systems". Systembegriff und Begriffssystem in Kants Transzendental-philosophie", en: Fulda, H.-F. \& Stolzenberg, J. (eds.) System der Vernunft. Kant und der deutsche Idealismus I. Architektonik und System in der Philosophie Kants. Hamburg: Meiner, 2001, pp. 53-72.

11. KrV A 491/B 519 así como también Prolegomena zu einer jeden künftigen Metaphysik (AA 04, 337).

12. Para la relación entre Kant y sus sucesores críticos ver Zöller, G., „Die Möglichkeiten und Grenzen der Vernunft. Kant und der deutsche Idealismus“, en: Vossenkuhl, W. \& Fischer, E. (eds.) Die Fragen der Philosophie. Vorlesungen zur Einführung in die Disziplinen und Epochen der Philosophie. München: Beck, 2003, pp. 295-312.

13. ZE, GA I/4, 230s. Ver además Zöller, G., "From Transcendental Philosophy to Wissenschaftslehre. Fichte's Modification of Kant's Idealism", en: European Journal of Philosophy 15 (2007), pp. 249-269.

14. Acerca del estatus del realismo en el idealismo alemán ver Zöller, G. "German Realism. The Self-Limitation of Idealist Thinking in Fichte, Schelling and Schopenhauer", en: Ameriks, K. (ed.) The Cambridge Companion to German Idealism. Cambridge: CUP, 2000, pp. 200-218.

15. AA 06:218 (Metaphysik der Sitten), así como también GA III/2, 298 y 300 (primer y segundo borrador respectivamente de una carta a J. Baggesen de abril o mayo de 1795).

16. Para este tema ver Zöller, G., „Am Anfang war ... die Tat. Der Primat des Praktischen und das Faktum der reinen Vernunft in der Philosophie Kants“, en: Mülder-Bach, I. \& Schumacher, E. (eds.) Am Anfang war.... Ursprungsfiguren und Anfangskonstruktionen der Moderne. München, Fink, 2008, pp. 91-105. Así como también del mismo autor: „Das »erste System der Freiheit«. Fichtes neue Darstellung der Wissenschaftslehre (1795-1899)“, en: Danz, Chr. \& Stolzenberg, J. (eds.) System und Kritik um 1800. Hamburg: Meiner, 2011, pp. 13-28.

17. WL-1804-II, GA II 8, 376.

18. $\mathrm{KrV}$ B XI.

19. Acerca de las metáforas conceptuales visuales de Fichte, ver Zöller, G. „Life into which an Eye has been inserted. Fichte on the Fusion of Vitality and Vision", en: Rivista di Storia della Filosofia 69 (2014), pp. 601-617.

20. Para esta cuestión ver Zöller, G. „Das Absolute und seine Erscheinung. Die SchellingRezeption des späten Fichte“, en: Jahrbuch des deutschen Idealismus/Yearbook of German Idealism 1 (2003), pp. 165-182. También del mismo autor: „Fichte, Schelling und die Riesenschlacht um das Sein“, en: Hiltscher, R. \& Klingner, S. (eds.) Friedrich Wilhelm Joseph Schelling. Neue Wege der Forschung, Darmstadt: Wissenschaftliche Buchgesellschaft, 2012, pp. 221-236; y Fichte lesen, Stuttgart-Bad Cannstatt: Fromann-Holzboog, 2013, pp. 47-59.

21. Acerca de las tres fases de la obra de Fichte en relación con un desarrollo de la obra análogo en Beethoven ver Zöller, G., "Parallelleben. Fichte und Beethoven“, en: Radrizzani, I., \& Oncina Coves, F., (eds.), Fichte und die Kunst. Fichte-Studien Jahrgang 25. 2014/1. Band 41. Amsterdam \& New York: Rodopi, 2014, pp. 279-301.

22. WL-1812, GA II/13, 48.

Revista de Estud(i)os sobre Fichte, 12 | 2016 
23. StL, GA II/16, 15.

24. Al respecto ver Zöller, G. : „»Freiheit aller von der Freiheit aller.« Das Reich des Rechts in Fichtes geschichtsphilosophischer Staatslehre“, en: Döring, T., Vinken, B. \& Zöller, G., (eds.), Übertragene Anfänge. Imperiale Figurationen um 1800. München: Fink, 2010, pp. 199-213; "Der Staat und das Reich. Fichtes politische Geschichtsphilosophie“, en: Zöller, G. Der Staat als Mittel zum Zweck. Fichte über Freiheit, Recht und Gesetz. Baden-Baden: Nomos, 2011, pp. 189-205; así como tambien „»Die beiden Grundprincipien der Menschheit«. Glaube und Verstand in Fichtes später Staatsphilosophie“, en: Gabriel, M., Halfwassen, J. \& Zimmermann, S., (eds.), Philosophie und Religion. Heidelberg: Universitätsverlag Winter, 2011, pp. 171-191.

25. StL, GA II/16, 21.

26. Respecto del concepto crítico de imagen en Fichte ver Zöller, G.: "Fichtebilderverbot. Historische und systematische Überlegungen zum philosophischen Umgang mit Fichtes Texten", en: Schnell, A. \& Kunes, J., (eds.), Bild, Selbstbewußtsein Einbildungskraft. Leiden und Boston: Brill, 2016, pp. 217-234.

27. StL, GA II/16, 17.

28. Idem.

29. Idem.

30. StL, GA II 16/23 (resaltado en el original).

31. StL, GA II 16/22 (resaltado en el original).

32. Ver StL, GA II 16/21.

33. StL, GA II/16, 21 (resaltado en el original).

34. StL, GA II/16, 22.

35. StL, GA II/16, 20.

36. StL, GA II/16, 27.

37. StL, GA II/16, 28 (resaltado en el original).

38. StL, GA II/16, 27.

39. StL, GA II/16, 29 (resaltado en el original).

40. StL, GA II/16, 29.

41. StL, GA II/16, 25.

42. StL, GA II/16, 27.

43. StL, GA II/16, 27.

44. StL, GA II/16, 27 (resaltado en el original).

45. Sobre el concepto central del querer en Fichte ver Zöller, G.,: "Thinking and Willing in Fichte's Theory of Subjectivity”, en: Breazeale, D. \& Rockmore, T., (eds.), New Perspectives on Fichte. Atlantic Highlands: Rodopi, 1995, pp. 1-18; "Bestimmung zur Selbstbestimmung. Fichtes Theorie des Willens", Fichte-Studien 7 (1995), pp. 101-118; Fichte's Transcendental Philosophy: The Original Duplicity of Intelligence and Will. Cambridge: Cambridge University Press, 1998; "Einheit und Differenz von Fichtes Theorie des Wollens", Philosophisches Jahrbuch 106 (1999), pp. 430-440; "Denken und Wollen beim späten Fichte“, Fichte-Studien 17 (2000), pp. 283-298; y "Thinking and Willing in Late Fichte“, en: Breazeale, D. \& Rockmore, T., (eds.), After Jena: New Essays on Fichte's Later Philosophy. Evanston, Ill: Northwestern University Press, 2008, pp. 51-66.

46. StL, GA II/16, 24 (resaltado en el original).

47. En relación con la crítica radical de Fichte a la metafísica onto-teológica ver Zöller, G., "Das proton pseudos der gewöhnlichen profanen Philosophie. Gott und Welt in Fichtes Erlanger Darstellung der Metaphysik“, en: Gerten, M., (ed.), Fichte in Erlangen 1805. Beiträge zu den FichteTagungen in Rammenau (19.-21. Mai 2005) und in Erlangen (1.-3. Dezember 2005). Amsterdam \& New York: Rodopi, 2009, pp. 359-379 así como "Ex aliquo nihil. Fichtes Antikreationismus", en: Asmuth, Ch. \& Drilo, K., (eds.), Der Eine oder der Andere. "Gott« in der klassischen deutschen Philosophie und im Denken der Gegenwart. Tübingen: Mohr, 2010, pp. 39-54.

48. GWL, GA I/2, 271. 
49. StL, GA II/16, 30 (resaltado en el original).

50. WL-1810, GA II/11, 318 (resaltado en el original).

51. StL, GA II/16, 15 (resaltado en el original).

52. GNR, GA I/3, 351.

53. Ver GdgZ, GA I/8, 313, ver también StL, GA II/16, 120 y 132.

54. StL, GA II/16, 54.

55. Para este tema ver Zöller, G., “[E]ine merkwürdige Antinomie der menschlichen Vernunft mit ihr selbst. Kant über das Verhältnis von historischem Kirchenglauben und reinem Religionsglauben“, en: Klemme, H., (ed.), Kant und das antinomische Denken. Berlin \& Boston: De Gruyter (en prensa).

\section{RESÚMENES}

This article discusses the purpose of Fichte of an "applied philosophy" aimed at reflecting the relationship between philosophical thinking (speculation) and the external reality to philosophy (life). The analysis focuses on the so-called Doctrine of the State (1813). The text is divided into four sections: 1) about the relationship between system and critique, 2) between system and selfcritique, 3) between system and life and, finally, 4) between pure and applied philosophy. It is argued that the philosophical legacy of the last Fichte consists of the vital validation of knowledge.

\section{ÍNDICE}

Keywords: life, system, Kant, Doctrine of the State 1813

\section{AUTORES}

\section{GÜNTER ZÖLLER}

München 